\title{
Process Modeling and Simulation of Cyclohexanone Production
}

\author{
Atthadej Kamchaddaskorn, Nalinee Mukdasanit, Thongchai Srinophakun \\ Department of Chemical Engineering, Faculty of Engineering, Kasetsart University \\ Bangkhen, Bangkok, Thailand \\ fengtcs@ku.ac.th
}

\section{Extended Abstract}

Typically, both cyclohexanone and cyclohexanol are intermediates in a sequence of the cyclohexane oxidation reaction. Therefore, in order to produce cyclohexanone, the conversion of this reaction needs to be kept in the range of 4$10 \%$ to avoid undesired products. The aim of this research is to propose the process model with alternative distillation sequences of cyclohexanone production plant. The advantage of heat-integrated distillation regarding to the cost of operation is studied. In this work, the cyclohexanone is synthesised by the oxidation of liquid cyclohexane based on well acceptable kinetic constants [1,2,3]. Feed stream includes cyclohexane, oxygen and nitrogen at 2268, 4536 and 454 $\mathrm{kmol} / \mathrm{hr}$. For the separation section, the optimal heat-integrated distillation sequence is formulated as a mixed integer nonlinear programming (MINLP) problem. Then overall process steady-state simulation and the comparison with and without heat integration are undertaken. Finally, process controllability by changing $\pm 0.1 \%$ of cyclohexane feed flowrate is performed [4].

Product stream of cyclohexanone synthesis section are unreacted cyclohexane, cyclohexanol, cyclohexanone, water, and cyclohexyl hydroperoxide at 2005, 11, 67, 67 and $185 \mathrm{kmol} / \mathrm{hr}$; respectively. In separation section, one optimal and four alternative sequences are obtained from optimization. The combination of these obtainable sequences with cyclohexanone synthesis section yields four alternative configurations of overall process [5]. Every configuration can separate the multicomponent product into pure component or reach $98 \%$ purity. In addition, the heat integration can reduce at the average $39 \%$ of reboiler hot utility consumption. The comparison between the combine of cyclohexanone synthesis section with and without heat integrated distillation sequence show that column reboiler duty of the process with heat integrated distillation sequence is less than the other one. Heat from column condenser can be used as supported heat for other column reboiler in the same sequence. Thus, it can be used for decrease the reboiler energy consumption. To analyze the controllability of cyclohexanone production process, the cyclohexanone feed flowrate is changed to less and more than its steady state value [6]. The test controllability is provided good controller responses. This approach presented the plantwide simulation and design in order to revamp the process under limitation of time and cost consumption.

\section{References}

[1] R. Pohorecki, J. Baldyga, W. Moniuk and P.T. Wierzchowski, "Kinetic model of uncatalyzed oxidation of cyclohexane," Chem. Eng. Res. Des., vol. 87, no. 3, pp. 349-356, 2009.

[2] R. Jevtic, P.A. Ramachandran and M.P. Dudukovic, "Effect of oxygen on cyclohexane oxidation: a stirred tank study," Ind. Eng. Chem. Res., 2009.

[3] A. Bhattacharya, "Modeling a continuous multistage liquid phase cyclohexane oxidation reactor network," Chem. Eng. Process, vol. 44, pp. 567-579, 2005.

[4] N. A. Mashayekhi, M. C. Kumg and H. H. Kung, "Selectivity oxidation of hydrocarbons on supported Au catalysts," Catal. Today, vol. 238, pp. 74-79, 2014.

[5] I. Rekkab-Hammoumraoui, A. Choukchou-Braham, L. Pirault-Roy and C. Kappenstein, "Catalytic oxidation of cyclohexane to cyclohexanone and cyclohexanol to tert-butyl hydroperoxide over Pt/oxide catalyst," Bull. Mater. Sci., vol. 34, no. 5, pp. 1127-1135, 2011.

[6] V. Govindan and A. K. Suresh, "Modelling liquid-phase cyclohexane oxidation," Ind. Eng. Chem. Res., vol. 46, no. 21, pp. 6891-6898, 2007. 